\title{
Earliest true moth lacewing from the Middle Jurassic of Inner Mongolia, China
}

Bingyu Zheng, Dong Ren, and Yongije Wang

Acta Palaeontologica Polonica 61 (4), 2016: 847-851 doi:http://dx.doi.org/10.4202/app.00259.2016

A new moth lacewing Guithone bethouxi gen. et sp. nov., is described from the Middle Jurassic Jiulongshan Formation (Inner Mongolia, China). This taxon is characterized by robust body, head retracted under pronotum, and remarkable costal space (expanded basad, narrowed distad). Herein, we propose a detailed definition of the lineages of Ithonidae sensu lato (moth lacewings, giant lacewings, and montane lacewings) based on extant groups in order to clarify the systematics of fossil species within the taxon. The comparison shows that Guithone bethouxi gen. et sp. nov. unquestionably represents the earliest true moth lacewing, implying that lineage differentiations within Ithonidae sensu lato must have taken place before the Middle Jurassic. Furthermore the new genus possessing some particular venation characters, such as irrecurrent humeral veinlet and simplified crossveination in radial sector, represents an important intermediate group in the evolution of Ithonidae sensu lato.

Bingyu Zheng [bingyu_zheng@163.com], Dong Ren [rendong@mail.cnu.edu.cn ], and Yongjie Wang [wangyjosmy@gmail.com] (corresponding author), College of Life Sciences, Capital Normal University, Beijing, 100048, China.

This is an open-access article distributed under the terms of the Creative Commons Attribution License (for details please see creativecommons.org), which permits unrestricted use, distribution, and reproduction in any medium, provided the original author and source are credited. 